\title{
SYSTEMATIC LITERATURE REVIEW (SLR): KEBERHASILAN DAN KEGAGALAN KINERJA BADAN USAHA MILIK DESA (BUMDES)
}

\author{
Ade Rani Aprillia ${ }^{1 *}$, Dwi Cahyono ${ }^{1}$, Ari Sita Nastiti ${ }^{1}$ \\ ${ }^{1}$ Universitas Muhammadiyah Jember, Jl. Karimata No. 49 Jember, Indonesia \\ "Korespondensi: aderaniaprillia9@gmail.com
}

\begin{abstract}
BUMDes has a role to realize the village economy. In improving the village economy, the government has the task of conducting socialization to the villagers through the provincial and district governments. The purpose of the systematic literature review is to determine the determinants of success and failure on the performance of BUMDes. Research data obtained from Google Scholar in 2016-2021 based on an initial search found as many as 484 articles and only 9 journals used as data sources and will be analyzed further. This study only uses research with a quantitative approach. The results of this study indicate that the failure factors that affect the performance of BUMDes are very diverse, namely motivation, education, age, and work experience. While the success factors that affect the performance of BUMDes are communication, AIS, HR, leadership style, motivation, work environment, salary, competence, organizational performance, commitment, organizational culture, training, the influence of job satisfaction, and GCG.
\end{abstract}

Keywords: Systematic Literature Review; BUMDes; The Success Of BUMDes; BUMDes Failure

\begin{abstract}
ABSTRAK
BUMDes memiliki peran untuk mewujudkan perekonomian desa. Dalam meningkatkan perekonomian desa pemerintah memiliki tugas untuk melakukan sosialisasi pada penduduk desa melalui pemerintah provinsi dan pemerintah kabupaten. Tujuan dari systematic literature riview adalah untuk menentukan faktor penentu keberhasilan dan kegagalan pada kinerja BUMDes. Data penelitian didapat dari Google Scholar tahun 2016-2021 berdasarkan pencarian awal ditemukan sebanyak 484 artikel dan hanya 9 jurnal yang digunakan sebagai sumber data dan akan dianalisis lebih lanjut. Kajian ini hanya menggunakan penelitian dengan pendekatan kuantitatif saja. Hasil studi ini jika faktor kegagalan yang memepengaruhi kinerja BUMDes sangat beragam yaitu motivasi, pendidikan, umur, dan pengalaman kerja. Sedangkan faktor keberhasilan yang mempengaruhi kinerja BUMDes yaitu komunikasi, SIA, SDM, gaya kepemimpinan, motivasi, lingkungan kerja, gaji, kompetensi, kinerja organisasi, omitmen, budaya organisasi, pelatihan, pengaruh kepuasan kerja, dan GCG.
\end{abstract}

Kata kunci: Review Sistematis Literatur; BUMDes; Keberhasilan BUMDes; Kegagalan BUMDes. 


\section{PENDAHULUAN}

Era otonomi yang terjadi telah banyak mendorong daerah untuk lebih memperhatikan nilai-nilai yang berguna untuk mencapai kesejahteraan masyarakat serta peningkatan yang lebih baik dalam bidang ekonomi, sosial maupun politik sesuai dengan pembangunan desa. (Aldila et al., 2018). Desa membutuhkan suatu badan usaha untuk mengelola potensinya, karena ekonomi desa selama ini mengalami keterpurukan. Jika dari sisi konsep (menurut UU dan PP), pembentukan BUMDes bertujuan untuk mewujudkan kesejahteraan masyarakat desa. Tetapi dalam penerapannya masih banyak daerah dan desa yang tidak memiliki prakarsa dan motivasi untuk mengembangkan BUMDes. Hal ini dipengaruhi oleh potensi dan kapasitas ekonomi masyarakat dalam mendesain serta mengelola ekonomi perdesaan (Qosjim, 2017). Berdasarkan data dari kementrian desa mengungkapkan mengenai pembangunan daerah tertinggal, dan transmigrasi setidaknya ada 45.549 BUMDes di Indonesia. Dalam hal ini ada 4,8 \% BUMDes tidak berjalan dan 36\% yang tidak memberikan kontribusinya, (CNN, 2019).

BUMDes tidak dapat berjalan sendiri tanpa adanya partisipasi pemerintah dan dukungan dari masyarakat desa. Indikator keberhasilan BUMDes dapat dilihat melalui meningkatnya laba/aset secara konsisten, meluasnya cangkupan konsumen, kemampuan karyawan dalam menjalankan tugas, dan memberikan dampak nyata bagi masyarakat. Keberhasilan BUMDes dapat memberikan dampak positif bagi pemerintah serta masyarakat desa yaitu meningkatkan perekonomian desa, meningkatkan pendapatan asli desa, meningkatkan pengelolaan potensi desa sesuai dengan kebutuhan masyarakat, dan menjadi tulang punggung pertumbuhan dan pemerataan ekonomi desa. Swandari et al. (2017) berpendapat bahwa salah satu cara untuk mencapai pertumbuhan ekonomi di wilayah pedesaan adalah melalui pertumbuhan lembaga mikro desa misalnya Badan Usaha Milik Desa. Sedangkan Ibnu \& Endaryanto (2018); Ihsan (2018); Jaryono \& Tohir (2019); Lestari (2017) berpendapat jika keberhasilan BUMDes didukung oleh kualitas sumber daya yang baik seperti sumber daya alam, sumber daya manusia , dan sumber daya finansial.

Oleh karena itu penelitian terkait keberhasilan BUMDes penting untuk dilakukan agar BUMDes dapat memperbaiki kinerja organisasi BUMDes, sehingga mampu meningkatkan pertumbuhan ekonomi di desa. Kajian ini akan mengulas dan menganalisis kembali dari berbagai penelitian terkait faktor keberhasilan dan kegagalan pada kinerja BUMDes menggunakan metode Systematic Literature review (SLR). Menurut Siswanto (2012) Systematic riview berguna untuk menghasilkan penelitian yang berkualitas. SLR merupakan metode penelitian yang mengulas kembali permasalahan tertentu yang menekankan pada pertanyaan tunggal yang telah diidentifkasi secara sitematis, dinilai dan disimpulkan menurut kriteria yang telah ditetapkan sebelumnya berdasarkan bukti dari penelitian yang berkualitas dan relevan (Latifah \& Ritonga, 2020). Dengan penggunaan metode SLR dapat dilakukan review dan identifikasi jurnal secara sistematis yang pada setiap prosesnya mengikuti langkah-langkah atau protokol yang telah ditetapkan. Selain itu, Metode SLR dapat menghindarkan dari identifikasi yang bersifat subjektif dan diharapkan hasil identifikasinya dapat menambah literatur tentang penggunaan Metode SLR dalam identifikasi jurnal (Triandini et al., 2019)

\section{METODE PENELITIAN}

Menurut (Kitchenham \& Charters, 2007) metode yang digunakan dalam penelitian ini yaitu Systematic literature review (SLR) atau dalam bahasa indonesia disebut tinjauan pustaka sistematis adalah metode literature review yang mengidentifikasi, menilai, dan menginterpretasi seluruh temuan-temuan pada suatu topik penelitian, untuk menjawab pertanyaan penelitian (research question). 


\section{Objek Penelitian}

Objek dalam penelitian ini adalah penelitian yang mengenai kegagalan dan keberhasilan kinerja pada Badan Usaha Milik Desa (BUMDes). Sedangkan subjek penelitian ini adalah Badan Usaha Milik Desa (BUMDes) di Indonesia.

\section{Teknik Pengumpulan Data}

Pengumpulan data yang digunakan dalam penelitian ini adalah studi pustaka, merupakan metode untuk memperoleh informasi dari teks-teks yang tertulis maupun soft copy edition, seperti buku-buku mengenai pemerintahan desa, publikasi pemerintah, undang-undang terkait, web browsing, serta jurnal terkait dengan variabel dan permasalahan yang berhubungan dengan penelitian ini.

\section{Research Question (Pertanyaan Peneliti)}

Research Question atau pertanyaan penelitian merupakan topik yang diminati dan dipilih peneliti. Berikut adalah Research Question dalam penelitian ini:

RQ 1: Apa saja faktor-faktor yang mempengaruhi kegagalan dalam menjalankan kinerja BUMDes?

RQ 2: apa saja faktor-faktor yang mempengaruhi keberhasilan dalam menjalankan kinerja BUMDes?

RQ 3: Siapa peneliti yang aktif dalam penelitian ini?

RQ 4: Apa metode yang digunakan dalam pengambilan data tentang kenerja BUMDes?

RQ 5: Apa saja permasalahan yang ditemukan dalam penelitian ini?

\section{Search Process (Proses Pencarian)}

Search Process (Proses Pencarian) dilakukan dengan menggunakan search engine (Google Chrom) dengan alamat situs https://scholar.google.co.id/ dan https://www.google.com dipilih karena saat ini merupakan basis data terbesar dan publikasi. String pencarian dengan menggunakan kata kunci sebagai berikut:

(Kinerja "Badan Usaha Milik Desa") dan (Faktor Keberhasilan BUMDes *ATAU Faktor Kegagalan BUMDes)

\section{Inclusion and Exclusion Criteria (Kriteria Batasan dan Pemasukan)}

Inclusion and exclusion criteria adalah tahap untuk menentukan apakah data layak atau tidak layak jika digunakan sebagai sumber data penelitian. Berikut kriteria data yang dikategorikan layak dalam penelitian yaitu:

1. Data yang digunakan dari tahun 2016-2021

2. Literature yang digunakan hanya paper jurnal yang berkaitan dengan kegagalan dan keberhasilan kinerja pada Badan Usaha Milik Desa (BUMDes)

\section{Quality Assesment}

Pada tahap ini data yang telah ditemukan akan dievaluasi berdasarkan pertanyaan penelitian berikut:

1. QA1 : Apakah paper jurnal diterbitkan pada rentang waktu 2015-2020?

2. QA2 : Apakah paper jurnal tersebut membahas mengenai analisis kinerja BUMDes?

3. QA3 : Apakah paper jurnal tersebut menuliskan mengenai BUMDes?

Dan setiap paper akan diberikan nilai berdasarkan pertanyaan diatas.

1. Ya (Y) : untuk paper jurnal yang sesuai dengan kriteria pertanyaan pada quality assessment.

2. Tidak (T) : untuk paper jurnal yang tidak sesuai dengan kriteria pertanyaan pada quality assessment. 


\section{Pengumpulan Data}

Pengumpulan data merupakan tahapan pengumpulan data-data yang digunakan dalam penelitian. Data yang dikumpulkan dalam penelitian ini adalah data sekunder. Data sekunder merupakan proses pengumpulan data yang dibutuhkan dalam penelitian ini. Pengumpulan data (data collection) dalam penelitian ini diperoleh dari beberapa tahap diantaranya yaitu : observasi, studi pustaka, dokumentasi

\section{Peta Pemikiran}

Peta pemikiran merupakan metode untuk memaksimalkan peneliti untuk mengetahui isi pemikiran yang ada.

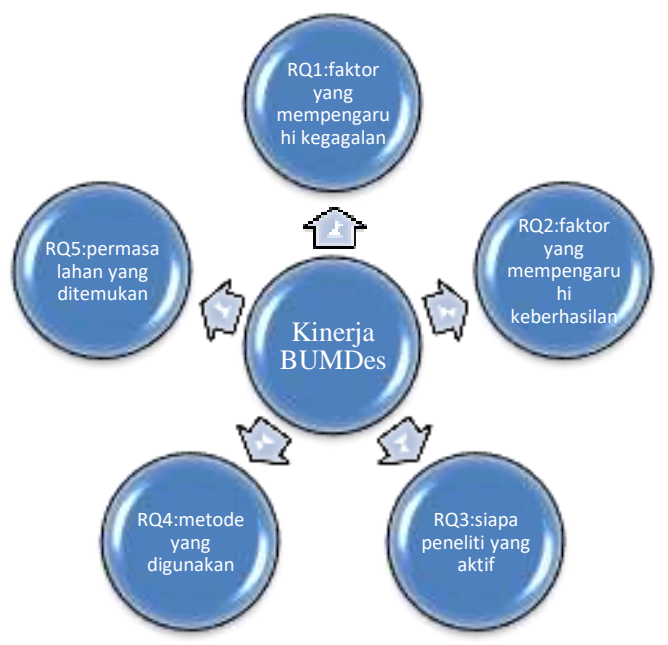

Gambar 1. Peta Pemikiran

\section{HASIL DAN PEMBAHASAN}

\section{Data Analysis}

Dalam tahap ini, data analisis dan hasilnya akan menjawab Research question (RQ) yang telah ditentukan dan akan membahas mengenai keberhasilan dan kegagalan pada kinerja Badan Usaha Milik Desa di Indonesia yang ada pada tahun 2016-2021.

\section{Hasil dari RQ1: Faktor-Faktor yang Mempengaruhi Kegagalan dalam Menjalankan Kinerja BUMDes}

Berdasarkan Research Question 1 yaitu mengenai faktor-faktor yang mempengaruhi kegagalan dalam menjalankan kinerja BUMDes maka dihasilkan dalam kategori paper jurnal berikut dapat terlihat dalam tabel 1 yang menunjukkan bahwa motivasi, pendidikan, umur, pengalaman kerja merupakan faktor yang mempengaruhi kegagalan dalam menjalankan kinerja BUMDes.

Tabel 1. Kategori Faktor yang Mempengaruhi Kegagalan dalam Menjalankan Kinerja BUMDes

\begin{tabular}{lllc}
\hline No. & Fakor Kegagalan & Peneliti & Jumlah \\
\hline 1. & Motivasi & (Ningsih,2016) & 1 \\
2. & Pendidikan & (Swandari,Setiawina dan Marhaeni,2017) & 1 \\
3. & Umur & (Swandari,Setiawina dan Marhaeni,2017) & 1 \\
4. & Pengalaman Kerja & (Swandari,Setiawina dan Marhaeni,2017) & 1 \\
5. & Gaya Kepemimpinan & (Swandari,Setiawina dan Marhaeni,2017) & 1 \\
\hline
\end{tabular}


Hasil dari RQ2: Faktor-Faktor yang mempengaruhi Keberhasilan dalam Menjalankan Kinerja BUMDes

Research Question 2 mengenai faktor-faktor yang mempengaruhi keberhasilan dalam kinerja BUMDes dapat menghasilkan kategori paper jurnal yang dapat dilihat dalam tabel 2 menunjukkan bahwa komunikasi, SIA, SDA, gaya kepemimpinan, motivasi, lingkungan kerja, gaji, kopentensi, kinerja organisasi, komitmen, budaya organisasi, pelatihan, komitmen, pengaruh kepuasan kerja ialah faktor yang mempengaruhi keberhasilan dalam kinerja BUMDes.

Tabel 2. Kategori Faktor yang Mempengaruhi Keberhasilan dalam Menjalankan Kinerja BUMDes

\begin{tabular}{|c|c|c|c|}
\hline No. & Faktor Keberhasilan & Peneliti & Jumlah \\
\hline 1. & Komunikasi & (Ningsih, 2016) & 1 \\
\hline 2. & $\begin{array}{l}\text { Sistem Informasi } \\
\text { Akuntansi }\end{array}$ & (Selamat, 2016) & 1 \\
\hline 3. & $\begin{array}{l}\text { Sumber } \\
\text { Manusia }\end{array}$ & $\begin{array}{l}\text { (Selamat, 2016), (furqon dan Qudbi, } \\
\text { 2018) }\end{array}$ & 2 \\
\hline 4. & Gaya Kepemimpinan & $\begin{array}{l}\text { (Selamat,2016), (furqon dan Qudbi, } \\
2018 \text { ), (Nisa, 2018), (Nurman, } \\
\text { Marnis dan Nas, 2019) }\end{array}$ & 4 \\
\hline 5. & Motivasi & $\begin{array}{lr}\text { (Selamat, } & \text { 2016), } \\
\text { (Swandari,Setiawina } & \text { dan } \\
\text { Marhaeni,2017), (Putra, Mahendra, } & \\
\text { Harwathy, 2021) }\end{array}$ & 3 \\
\hline 6. & Lingkungan Kerja & $\begin{array}{l}\text { (Swandari,Setiawina dan } \\
\text { Marhaeni,2017) }\end{array}$ & 1 \\
\hline 7. & Gaji & $\begin{array}{l}\text { (Swandari,Setiawina } \\
\text { Marhaeni,2017) }\end{array}$ & 1 \\
\hline 8. & Kopetensi & $\begin{array}{l}\text { (Nisa, 2018), (Putra, Hendriani dan } \\
\text { Samsir, 2020) }\end{array}$ & 2 \\
\hline 9. & Kinerja Organisasi & (Nisa, 2018) & 1 \\
\hline 10. & Komitmen & $\begin{array}{l}\text { (Harni Ningsih, 2016), (Nurman, } \\
\text { Marnis dan Nas, 2019), (Putra, } \\
\text { Hendriani dan Samsir, 2020) }\end{array}$ & 2 \\
\hline 11. & Budaya Organisasi & $\begin{array}{l}\text { (Nurman, Marnis dan Nas, 2019), } \\
\text { (Putra, Mahendra, Harwathy, 2021) }\end{array}$ & 2 \\
\hline 12. & Pelatihan & (Putra, Hendriani dan Samsir, 2020) & 1 \\
\hline 13. & $\begin{array}{l}\text { Pengaruh Kepuasan } \\
\text { Kerja }\end{array}$ & (Putra, Mahendra, Harwathy, 2021) & 1 \\
\hline
\end{tabular}

\section{Hasil dari RQ3: Peneliti Aktif dan Berpengaruh}

Studi primer yang telah dipilih selanjutnya diolah berdasarkan peneliti yang baik dan sangat aktif dalam keberhasilan dan kegagalan pada kinerja BUMDes di Indonesia dapat di identifikasi pada gambar 2 yang menunjukkan peneliti pertama dan bukan peneliti pertama yang sangat aktif dan juga berpengaruh. Pada gambar menunjukkan bahwa tidak ada peneliti yang aktif dan berpengaruh karena semua peneliti hanya meneliti satu (1) paper jurnal mengenai keberhasilan dan kegagalan pada kinerja Badan Usaha Milik Desa di Indonesia. 


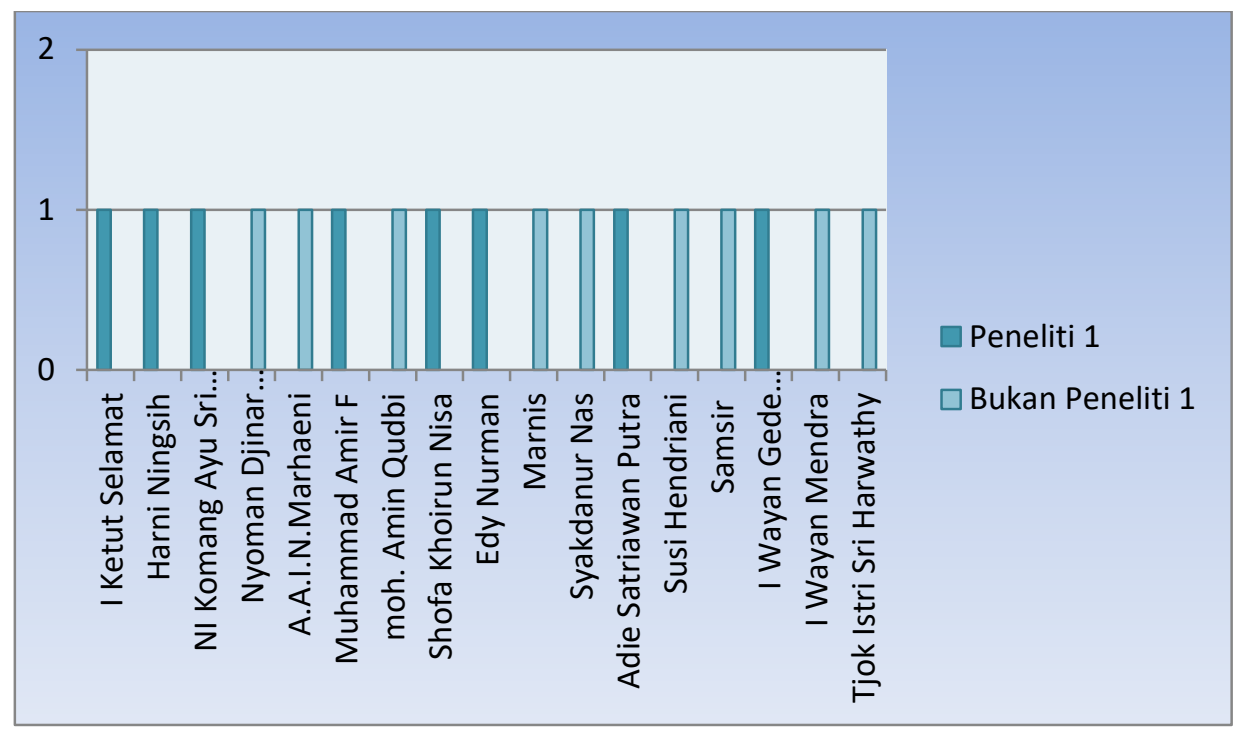

Gambar 2. Peneliti dan Jumlah Karyanya

\section{Hasil dari RQ4: Teknik Pengumpulan Data}

Berdasarkan teknik pengumpulan data untuk penelitian mengenai keberhasilan dan kegagalan pada kinerja Badan Usaha Milik Desa di Indonesia, diperoleh hasil yaitu kategori paper jurnal berdasarkan teknik pengumpulan data yang dapat dilihat dalam tabel 3 menunjukkan bahwa,

Tabel 3. Kategori Teknik Pengumpulan Data

\begin{tabular}{|c|c|c|c|c|}
\hline No. & $\begin{array}{c}\text { Teknik } \\
\text { Pengumpulan } \\
\text { Data }\end{array}$ & $\begin{array}{c}\text { Jumlah } \\
\text { Responden }\end{array}$ & Peneliti & Tahun \\
\hline 1. & & 47 & I Ketut Selamat & 2016 \\
\hline 2. & & 30 & Harni Ningsih & 2016 \\
\hline 3. & & 100 & $\begin{array}{l}\text { Ni Komang Ayu Sri } \\
\text { Swandari, Nyoman } \\
\text { Djinar Setiawan, } \\
\text { A.A.I.N.Marhani }\end{array}$ & 2017 \\
\hline 4. & & 40 & $\begin{array}{l}\text { Mohammad Amir } \\
\text { Furqon, Moh. Amin } \\
\text { Qudbi }\end{array}$ & 2018 \\
\hline 5. & Kuisioner & 78 & Shofa Khoirun Nisa & 2018 \\
\hline 6. & & 208 & $\begin{array}{l}\text { Edy } \\
\text { Marnis, Syakdanur } \\
\text { Nas }\end{array}$ & 2019 \\
\hline 7. & & 118 & $\begin{array}{lr}\text { Adie } & \text { Satriawan } \\
\text { Putra, } & \text { Susi } \\
\text { Hendriani, } & \text { Samsir }\end{array}$ & 2020 \\
\hline 8. & & 55 & $\begin{array}{l}\text { I Wayan Gede } \\
\text { Cahyana Putra, I } \\
\text { Wayan Mendra, } \\
\text { Tjok Istri Sri } \\
\text { Harwathy }\end{array}$ & 2021 \\
\hline
\end{tabular}




\section{Hasil dari RQ5: Topik dan Metode Penelitian}

Hasil dari penelitian mengenai keberhasilan dan kegagalan pada kinerja Badan Usaha Milik Desa di Indonesia akan dijelaskan pada tabel 4.3.5, analisis studi primer yang dipilih yaitu menjelaskan bahwa penelitian ini berfokus pada

1. Mengidentifikasi paper jurnal dengan metode kuantitatif, dan mengidentifikasi permasalahan mengenai keberhasilan dan kegagalan pada kinerja BUMDes di Indonesia.

2. Menemukan penyebab terjadinya kegagalan pada kinerja BUMDes di Indonesia.

3. Mencari solusi dari permasalahan yang ada.

4. Membuat kesimpulan mengenai penyebab kegagalan dan solusi jawaban yang terbaik dari penelitian mengenai keberhasilan dan kegagalan pada kinerja Badan Usaha Milik Desa di Indonesia.

\section{PEMBAHASAN}

Pada pembahasan pertama yaitu mengidentifikasi permasalahan terkait keberhasilan dan kegagalan kinerja pada BUMDes di Indonesia. Hasil dalam pemeriksaan ini menunjukkan bahwa motivasi kinerja berpengaruh signifikan terhadap kinerja karyawan karena motivasi kerja karyawan berbeda satu dengan lainya, akan tetapi motivasi merupakan sifat atau karateristik seseorang (Selamat, 2016). Pengalaman kerja, gaji, lingkungan kerja serta gaya kepemimpinan juga berpengaruh terhadap motivasi kinerja karyawan (Swandari et al., 2017). Hal ini didukung oleh putra (2021) semakin tinggi motivasi karyawan dalam bekerja akan meningkatkan kinerja karyawan, dengan adanya motivasi kerja yang tinggi akan memberikan dorongan kepada karyawan untuk terus meningkatkan kinerja mereka. Hasil penelitian ini tidak mendukung Ningsih (2016) membahas mengenai motivasi bahwa fasilitator tidak semata-mata memberikan motivasi kepada pengurus diharuskan meningkatkan kesadaran pengurus dalam melakukan kinerjanya. Penelitian terkait kompetensi dibahas oleh Nisa (2018) mengatakan jika kopetensi masing-masing individu dapat dikembangkan dalam upaya meningkatkan standar kinerja pegawai untuk mencapai tujuan organisasi. A S Putra \& Hendriani (2020) menguatkan jika kopetensi berpengaruh signifikan terhadap kinerja karyawan, yang dibuktikan dengan nilai koefisien jalur sebesar 1.186 dan signifikan pada p-value yang baik dan mampu untuk bekerja. Komitmen organisasi dari setiap karyawan diperlukan selain budaya organisasi dalam upaya meningkatkan kinerja Badan Usaha Milik Desa secara berkesinambungan untuk tetap konsisten melaksanakan tugas dan tanggung jawab sesuai dengan peraturan yang ada serta mampu bekerja dengan baik didalam organisasi ditambah dengan adanya dengan komitmen organisasi, secara tidak langsung kopetensi melalui komitmen organisasi berpengaruh signifikan terhadap kinerja, kopetensi seseorang dapat dilihat tingkat kreatifitas dan inovasi dalam menyelesaikan masalahnya (Nisa, 2018; Nurman et al., 2019; Putra \& Hendriani, 2020; Sumitariani \& Adiputra, 2020). Penelitian terkait budaya organisasi berpengaruh atas komitmen karyawan, dalam budaya karyawan juga perlu adanya seorang pimpinan dan karyawan memiliki kepedulian terhadap organisasi, jika semakin baik penerapan budaya organisasi maka akan semakin maka akan meningkat pula kinerja karyawan (Nurman et al., 2019; Sumitariani \& Adiputra, 2020; Triandini et al., 2019). Selanjutnya penelitian terkait kepuasan kerja yang dipaparkan oleh putra (2021) bahwa kepuasan kerja berpengaruh positif dan signifikan terhadap kinerja karyawan, dapat diartikan bahwa jika semakin tinggi kepuasan kerja karyawan maka akan meningkatkan kinerja karyawan BUMDes. Sumitariani \& Adiputra (2020) mengulas agar BUMDes dapat meningkatkan penerapan faktor-faktor pencegahan fraud seperti budaya organisasi, good 
corporate governance dan kopetensi sumber daya manusia, sehingga dapat mencegah kecurangan dalam organisasi.

Permasalahan topik kedua yaitu penyebab terjadinya kegagalan pada kinerja BUMDes di Indonesia adalah motivasi kerja terhadap kinerja karyawan (Ningsih, 2016). Selanjutnya penelitian dari Swandari et al. (2017) mengenai pendidikan bahwa tingkat pendidikan bukan faktor utama untuk meningkatkan tingkat prestasi kinerja karyawan, karena prestasi karyawan akan muncul bila ada keinginan seorang karyawan untuk meningkatkan prestasinya. Sedangkan faktor umur bahwa pegawai yang umur diatas 60 tahun akan menurun semangat kerjanya mereka cenderung tidak menginginkan dan meningkatkan kinerjanya, mereka hanya menikmati hasil kerja serta tidak memiliki keinginan bersaing dengan karyawan lainya (Swandari et al., 2017). Serta pengalaman kerja kurang mempengaruhi kinerja karyawan, meningkatnya kinerja karyawan BUMDes lebih mempengaruhi karena adanya dorongan dari individu masing-masing untuk bekerja lebih baik untuk mencapai hasil yang maksimal tanpa memandang lama atau banyaknya pengalaman kerja yang dimiliki karyawanya (Swandari et al., 2017).

Topik ketiga yaitu memilih solusi dan jawaban dari permasalahan kegagalan pada kinerja BUMDes di Indonesia. Selamat (2016); Swandari et al. (2017) mengatakan perlu adanya penataan manajemen, tertib administrasi, perubahan dalam pencatatan dengan menggunakan Sistem Informasi Akuntansi untuk mencegah adanya kecurangan, sehingga BUMDes mampu berkembang dengan baik serta pihak BUMDes harus lebih proaktif dalam memberikan informasi mengenai usaha. Dalam upaya meningkatkan kinerja organisasi harusnya memberikan fasilitas yang lebih kepada anggota untuk mengembangkan usaha sehingga akan banyak masyarakat atau Sumber Daya Manusia yang ikut terlibat (Nisa, 2018). Memberikan pelatihan serta meningkatkan pendidikan karyawan dalam usaha meningkatkan kopetensi kinerja karyawan dan selalu membantu karyawan apabila mengalami permasalahan sehingga dapat menyelesaikan pekerjaan dengan tepat waktu (Nurman et al., 2019; putra et al., 2021; A S Putra \& Hendriani, 2020; Swandari et al., 2017).

Pembahasan keempat adalah kesimpulan mengenai penyebab kegagalan dan solusi jawaban yang terbaik pada kinerja Badan Usaha Milik Desa di Indonesia yaitu dengan cara memberikan pelatihan untuk meningkatkan kompetensi kinerja pegawai untuk mencapai tujuan organisasi, pemilihan gaya kepemimpinan yang tepat untuk memberikan kepuasan sehingga produktifitas masyarakat dapat meningkat, adanya perlindungan kerja terhadap karyawan dan selalu memperhatikan kinerja karyawan, serta perbaikan budaya organisasi karena semakin baik budaya organisasi maka komitmen dan kinerja karyawan akan semakin tinggi (Nisa, 2018; Nurman et al., 2019; putra et al., 2021; A S Putra \& Hendriani, 2020; Swandari et al., 2017)

\section{SIMPULAN}

Berdasarkan hasil penelitian yang telah dilakukan, maka dapat di ambil kesimpulan bahwa penelitian ini menggunakan metode Systematic Literature Review (SLR) yang bertujuan untuk meninjau, menilai, serta menganalisis kembali melalui temuan-temuan yang diidentifikasi secara sistematis berdasarkan dari bukti peneliti terdahulu. Data analisis mengenai faktor kegagalan BUMDes, faktor keberhasilan BUMDes, peneliti aktif dan berpengaruh, teknik pengumpulan data, topik dan metode penelitian, Paper jurnal yang digunakan dalam penelitian ini sebanyak 8 paper jurnal dalam rentang waktu 2016-2021 yang diperoleh melalui hasil seleksi pencarian.

Hasil dari Research question (RQ:1) pada publikasi jurnal yang signifikan bahwa faktor yang mempengaruhi kegagalan dalam menjalankan kinerja Badan 
Usaha milik Desa di Indonesia yaitu motivasi, pendidikan, umur, pengalaman kerja, gaya kepemimpinan. Selanjutnya Research Question (RQ:2) faktor yang mempengaruhi keberhasilan dalam menjalankan kinerja BUMDes di Indonesia yaitu komunikasi, Sistem Informasi Akuntansi, Sumber Daya Manusia, motivasi, lingkungan kerja, gaji, kompetensi, kinerja organsisasi, komitmen, budaya organisasi, pelatihan, pengaruh kepuasan kerja. Research Question (RQ:3) memberitahukan bahwa tidak ada peneliti yang aktif dan berpengaruh karena semua peneliti hanya meneliti satu paper jurnal mengenai keberhasilan dan kegagalan pada kinerja BUMDes di Indonesia. Research Question (RQ:4) menunjukkan bahwa tektik pengumpulan data yang dilakukan semua peneliti menggunakan metode kuesioner dibandingkan menggunakan metode lainya. Dan yang terakhir yaitu Research Question (RQ:5) untuk topik yang paling sering diteliti yaitu mengenai pengaruh kepemimpinan dan kepuasan kerja karyawan dimana jika semakin baik pemimpin maka akan semakin tinggi tingkat kinerja karyawanya, organisasi juga perlu melakukan dorongan terhadap pegawai agar menjalankan tugasnya dengan baik untuk mencapai tujuan bersama. Paper jurnal yang diambil hanya metode kuantitatif karena metode ini mempunyai tahapan yang rutut dan sistematis dalam menyajikan fakta.

Metode Systematic Literature Review ini memiliki keterbatasan yaitu pada kata kunci yang terbatas yang menggunakan database (Google Scholar), walaupun penelitian ini juga menggunakan perangkat lunak formal sebagai alat bantu (Publish or Perish) peneliti masih memiliki kekurangan dalam menemukan jurnal yang sesuai dengan topik yang diteliti. Saran untuk penelitian selanjutnya diharapkan untuk meggunakan kata kunci yang lebih luas, serta memperbanyak menggunakan database, menentukan topik yang sesuai dan tepat, menggunakan paper jurnal dengan metode kuantitatif dan kualitatif agar data yang digunakan banyak serta semakin lengkap. Hal ini dapat memudahkan peneliti dalam memberikan penjelasan yang lebih rinci terkait permasalahan faktor keberhasilan dan kegagalan pada kinerja Badan Usaha Milik Desa (BUMDes) di Indonesia.

\section{DAFTAR RUJUKAN}

Aldila, B., Nikmatullah, D., \& Hasanuddin, T. (2018). Faktor-Faktor Yang Berhubungan Dengan Peranan Pengurus Badan Usaha Milik Pekon Di Pekon Gisting Bawah. Jurnal Ilmu-Ilmu Agribisnis, 6(2), 214-221.

CNN Indonesia. (2019). Jokowi Temukan 2.188 BUMDes “Ambyar.” CNN Indonesia.

Ibnu, M., \& Endaryanto, T. (2018). Penjelasan (explanation) Mengenai Tingkat Keberhasilan Badan Usaha Milik Desa (BUMDes). September.

Ihsan, A. N. (2018). Analisis Pengelolaan Badan Usaha Milik Desa ( BUMDes ) Gerbang Lentera Sebagai Penggerak Desa Wisata Lerep. Journal of Politic and Government Studies, 7(4), 11.

Jaryono, J., \& Tohir, T. (2019). Analisis Kinerja BUMDes "Mitra Usaha Makmur" dalam Pengaruhnya Terhadap Pendapatan Asli Desa (PADes) Desa Susukan Kecamatan Sumbang Kabupaten Banyumas. Sustainable Competitive Advantage (SCA), 9(23), 23-30.

Kitchenham, B. A., \& Charters, S. (2007). Guidelines for performing systematic literature reviews in software engineering technical report. In Software Engineering Group, EBSE Technical Report ....

Latifah, L., \& Ritonga, I. (2020). Systematic Literature Review (SLR): Kompetensi Sumber Daya Insani Bagi Perkembangan Perbankan Syariah Di Indonesia. Al Maal: Journal of Islamic Economics and Banking, 2(1), 63. 
https://doi.org/10.31000/almaal.v2i1.2763

Lestari, N. P. (2017). Social Institution Assignment.

Ningsih, H. (2016). Pengaruh Motivasi dan Komunikasi terhadap Kinerja Pengurus BUMDes Timur Sejahtera Desa Ujungbatu Timur. 1-10.

Nisa, S. K. (2018). TINGKAT KINERJA ORGANISASI BADAN USAHA MILIK DESA ( Studi Pada BUMDes Maju Makmur Desa Minggirsari Kecamatan Kanigoro Kabupaten Blitar ). Kebijakan Dan Manajemen Publik, 6(3), 1-12.

Nurman, E., Marnis, M., \& Nas, S. (2019). Pengaruh Kepemimpinan, Budaya Organisasi Terhadap Kinerja Karyawan Melalui Komitmen Pada Badan Usaha Milik Desa (Bum .... Jurnal Tepak Manajemen Bisnis, XI(1).

putra, i wayan gede cahyana. (2021). PENGARUH KEPUASAN KERJA, MOTIVASI DAN BUDAYA ORGANISASI TERHADAP KINERJA KARYAWAN PADA BUMDES DESA AAN I Wayan Gede Cahyana Putra 1 , I Wayan Mendra 2 , Tjok Istri Sri Harwathy 3 Fakultas Ekonomi dan Bisnis Universitas Mahasaraswati Denpasar. 2(1996).

Putra, A. S., \& Hendriani, S. (2020). Pengaruh Pelatihan dan Kompetensi terhadap Kinerja Karyawan yang Dimediasi oleh Komitmen pada Pengelola Bumdes di Kabupaten Kuansing. Jurnal Ekonomi KIAT, 31(2), 91-99.

Qosjim, A. (2017). Analisis Kinerja BUMDes di Kabupaten Lumajang ( Performance Analysis BUMDes in Jember District ). Journal Ekuilibrium, II(1), 10-17.

Selamat, I. K. (2016). Pengaruh efektivitas penerapan sistem informasi akuntansi dan motivasi kerja terhadap kinerja karyawan pada BUMDes se-Kecamatan Banjar Kabupaten Buleleng. Jurnal Akuntansi Profesi, 7(2), 12-20.

Siswanto, S. (2012). Systematic Review Sebagai Metode Penelitian Untuk Mensintesis Hasil-Hasil Penelitian (Sebuah Pengantar). Buletin Penelitian Sistem Kesehatan, 13(4). https://doi.org/10.22435/bpsk.v13i4

Sumitariani, N. K., \& Adiputra, I. M. P. (2020). Faktor-faktor Penentu Keberhasilan Pencegahan Fraud Pengelolaan Dana BUMDes. Ekuitas: Jurnal Pendidikan ..., $8(2), 167-175$.

Swandari, N. K. A. S., Setiawina, N. D., \& Marhaeni, A. A. I. N. (2017). Analisis FaktorFaktor Penentu Kinerja Karyawan BUMDes di Kabupaten Jembrana. Jurnal Ekonomi Dan Bisnis, 4(VOLUME.06.NO.04.TAHUN 2017), 1365-1394.

Triandini, E., Jayanatha, S., Indrawan, A., Werla Putra, G., \& Iswara, B. (2019). Metode Systematic Literature Review untuk Identifikasi Platform dan Metode Pengembangan Sistem Informasi di Indonesia. Indonesian Journal of Information Systems, 1(2), 63. https://doi.org/10.24002/ijis.v1i2.1916 